\title{
Kondratieff's Economic Waves and Future Scenarios Planning: an approach for organizations
}

Marcos Ferasso and Eloisio Andrey Bergamaschi

\author{
" Those who do not learn history are doomed to repeat it." \\ George Santayana
}

\begin{abstract}
This manuscript aims to present connections between scenario building techniques and Kondratieff's long economic waves, as a way of identifying patterns in medium and long-term planning for companies' future scenarios. This essay considers two different conceptual contributions to improve forecasting on organizations taking as a departure point Kondratieff's economic waves and Schwartz's future scenario planning. Analyzing these two theoretical contributions, we concluded that the information obtained through the path of Kondratieff's waves can delineate future scenarios as a way to anticipate challenges, opportunities, and threats for organizations' contingency planning. As a contribution for practitioners, considering these two approaches together enables greater performance for strategic planning of future scenarios that can be applied by organizations across a range of industries.
\end{abstract}

\section{Introduction}

Thinking about the future is clearly not a new subject. Ancient Greeks sought inspiration for their doubts about the future in the Oracle of Delphi, one of humanity's early efforts to better understand the future. Nowadays, looking for anticipatory trends and trying to understanding the pathways of technological changes, with a wide range of future possibilities, constitute practical and pressing challenges for managers. This makes them a central theme for organizations and nations who care about the way they navigate forwards.

The need to reduce the uncertainties and risks, the growing economic competitiveness on national and international levels, and the need to anticipate trends, and verify new opportunities have highlighted the importance of visualizing the future and learning from it (Nefiodow \& Wilenius, 2017).

According to Coates (2003), knowledge generated by exploring the future has direct implications for the planning the present. Otherwise, activities that regard thinking about the future, will be seen as mere entertainment that brings ineffective results to organizations.
Despite many planning efforts and goodwill, organizations of all kinds are nevertheless subject to decline and may face the threat of financial bankruptcy. The need to study the future becomes relevant for its contribution to the strategic planning of organizations. The main point concerning planning failures is that usually only one person, or a small group of people with leading roles, drive the future success of a project, plan, or even an entire organization. Another reason to explore the future is to help people discover their own assumptions.

A technology assessment must be taken into account when considering the need for investment in technology to achieve a promising outcome. To conduct such an assessment future scenarios and Kondratieff's waves offer two approaches that fulfil the need for decision makers in choosing among technologies for investment. Nefiodow and Nefiodow (2014) stressed the need to consider long-term macroeconomic scenarios in conjunction with innovation and technology challenges, thus evidences the need for further development of this combination approach.

We focus in the paper on long economic waves. The Russian economist Nikolai Kondratieff sought to 


\section{Kondratieff's Economic Waves and Future Scenarios Planning: an approach for organizations Marcos Ferasso and Eloisio Andrey Bergamaschi}

empirically demonstrate a pattern of repetition in a series of events throughout history. The coincidences of these events, evidenced empirically, seemed to Kondratieff to demonstrate the behavior of expansion and economic recession. The study of long economic waves allows a projected extrapolation of this behavior for future periods (Kondratieff, 1935; Grinin, et al., 2016).

Analyzing the long economic waves proposed by Kondratieff can be useful for building a process for future scenarios. The waves bring elements that have already been empirically tested, and at least partially validated over the years. However, our analysis also addresses the impact of the changes that new information and communication technologies (ICTs) have brought to the acceleration of knowledge diffusion process on new technologies. This has consequently reduced the waves' periods, and often leads to changes in the economic and technological scenarios.

From these contributions, arises our research question: How can Kondriatieff's long economic waves foster future scenarios planning for organizations' technology assessment?

The aim of this research is to present a connection between scenario-building techniques, and Kondratieff's long economic waves. This is done to identify patterns in medium and long-term future planning scenarios for companies. In the first part of the article, we introduce future studies on a theoretical level, thus emphasizing the construction of scenarios techniques. Further, we give a brief exposition about Kondratieff's work on long economic waves. The relation between these two, a theory and a technique, is presented at the end of this paper, demonstrating how to use the Kondratieff waves view as a way to support the improved construction of future scenarios.

The originality of this manuscript lies in joining a theory and a technique for helping the forecasting of organizations' decision-makers. We combined Kondratieff's waves and future scenarios planning in order to help practitioners identify patterns in economic waves that can be useful for forecasting. Thus, the ideas presented below intend to address companies that already use scenario planning, since some decisionmakers may show a bounded recognition of 'cyclical' patterns instead 'wave-shaped lines', or other patterns. We believe that that considering and identifying patterns is a basic task in scenario planning, and also that Kondratieff's theory provides key support for forecasting and scenario planning techniques. This approach presented in this paper can be used or applied in contrast with predictive analytics, forecasting, foresight, and prospecting analyses.

This manuscript builds upon theoretical precepts by advancing ideas (Knorr \& Verba, 2019), in a way that mainly links two different considerations from the fields of strategy and economics. The authors selected core theoretical contributions from a range of literature in both fields, in order to establish lines of thought and abstractions.

This manuscript is structured as follows. After introducing the theme and the need for greater exploration, we start reconceptualising the literature on future studies, stressing how to conceive of future building alternatives. We then briefly explore technology assessment, forecasting, foresight, and the construction of future scenarios concepts and approaches. After reviewing the literature on future studies, we present Kondratieff's economic waves, mainly focusing on the patterns he identified, in light of the growing pace of pattern change identified in the so-called fifth and sixth economic waves. The next section builds the edge of future scenarios techniques with Kondratieff's waves. In the last section of paper follows the conclusion, including suggestions for further studies.

\section{Studies about the Future}

For decades, organizations have been trying to incorporate predictions or visions about the future into their planning processes. Such knowledge allows organizations to make decisions that enable them to exploit advantages for future opportunities, as well as anticipate threats to enable them to be overcome. Prospective analysis is a solid basis for institutional sustainability, that helps to produce a more systematic understanding of organizational environments, including variables of behaviour, which are relevant for defining forward-looking institutional strategies (Castro \& Lima, 2001).

The future is something that does not exist and cannot be achieved, since when the future has finally arrived, it will be the present that is reached, not the future (Marinho \& Quirino, 1995 as cited in Castro \& Lima, 2001). So, studying the future involves images or perceptions about this future, which can make an impact on present actions, for both individual persons and the organizations concerned.

Future studies as a field involves techniques for probing, 


\section{Kondratieff's Economic Waves and Future Scenarios Planning: an approach for organizations Marcos Ferasso and Eloisio Andrey Bergamaschi}

experimenting, pushing, and engaging people. As underlined by Coates (2003), "one principal reason for studying the future is to widen intellectual horizons and make people aware of factors outside of their normal expert concerns that may converge on their interests in anywhere from 5 to 50 years, presenting an opportunity or a substantial risk, or demanding change for other reasons". Future studies thus may bring up relevant issues to the organisation's future (Coates, 2003), to help awaken to what they believe, as a way to make it explicit to themselves and to the group in which they work.

Here we raise the idea of 'multiple and uncertain futures' (Figure 1), where a projection from the past is one of several possibilities. This way, interaction between historical tendencies and hypothetical events determines the future (Castro \& Lima, 2001).

The term 'technological prospecting' refers to activities that focusing prospectively on technological changes, changes in functional capacity, or on the timing and significance of an innovation. Technological prospecting aims to predict possible future states of technology, or conditions that affect an innovation's contribution to an established goal (Coelho, 2003).

Technological prospecting is related to economic and social prospecting. Economic prospecting is relevant, since decision makers must make the best use of available resources for commercializing or using a technology. Thus, managers must know the costs of technology, human capital, and infrastructure that will be involved, as well as understanding the forces that guide the market.

Although there is no consensus, some prospective approaches can be distinguished, albeit sometimes applied without distinction (MDIC/STI, 2001):

- Technology Assessment: monitoring and identifying signs of change, carried out in a more or less systematic and continuous way;

- Forecasting: considering historical information, mathematical modeling, trends and analysis of future projections and hypothetical situations, normally executed periodically; and

- Foresight: developed mainly through the interactive work of specialists, oriented to anticipate possibilities on innovations, not necessarily based on trend information, but rather on speculative projections of their own knowledge, occurring in a non-systematic way.

The prospecting model aims to identify a desirable future among viable alternatives. This implies characterizing an articulated system of actors (involving interests, alliances, and conflicts) and variables (tendencies and ruptures) that influence the desired future, and to expand situations for this system to become compatible with it. Once the discrepancies between the present situation and the future objective have been considered and identified, strategies adopted in the present should then be established to lead to constructing the desired future (MDIC/STI, 2001).

One attempt to study the future can be found in the field of economics. Economists such as Nikolai Kondratieff tried to determine the cyclic occurrence of events in a way of predicting future economic waves. Although Kondratieff was successful in his attempts, his empirical evidences were proven in a period where technology development was growing in a more predictive scenario.
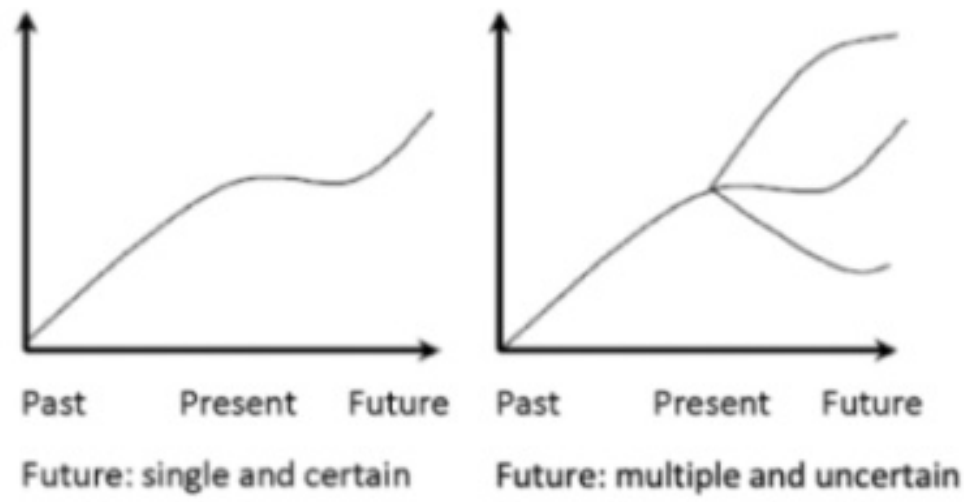

Figure 1. Future building alternatives Source: adapted from Castro and Lima (2001). 


\section{Kondratieff's Economic Waves and Future Scenarios Planning: an approach for organizations Marcos Ferasso and Eloisio Andrey Bergamaschi}

This is the reason why we need to emphasize technology assessment, forecasting and foresight.

\subsection{Technology assessment and forecasting}

The term "technology assessment" is known globally in government, politics, and business communities. According to Blair (1994), the concept spread in the late 1960s and began to be applied by the Office of Technology Assessment (OTA) in the United States in 1972. Since technological development has increased at growing rates, anticipating the consequences of its applications became a crucial theme for determining public policies related to current and future problems. Technology assessment aims to study the potential consequences of employing new technologies, in order to provide earlier indications of likely benefits or adverse impacts of a technology's applications.

The National Science Foundation defines technology assessment as a study of policies intended to better understand the consequences for society, regarding the extension of existing technologies or the introduction of new ones, whose effects usually would not be planned or anticipated (Coates, 2004).

The prospective approach to forecasting is closely connected with prediction, dating back to a tradition primarily concerned with building models that define causal relationships of scientific and technological developments, and with sketching probabilistic scenarios about the future. Nowadays, future developments are increasingly understood as being a systemic outcome of multiple factors and decisions. This means that political and social elements must be taken into account, rather than just obeying technical issues. Flexibility is gained by emphasizing the importance of combining results from various methods, also reducing the deterministic character traditionally associated with forecasting (Salles-Filho et al., 2001).

Some traditional forecasting tools may be appropriate under given conditions in stable economies. However, when facing volatile periods of economic crisis and turbulent environments, as with many countries in recent decades, quantitative models of forecasting alone lose value. Another constraint arises when dealing with emerging and rapidly changing industries, such as information technology and biotechnology, since results can be seemingly unexpected. Thanks to the advent of new information technologies, along with current renewable energies, smart grids, and cloud computing (to name a few), the creation of more elaborated models based in multiple variables has helped researchers to reduce errors previously associated with foresight.

\subsection{Foresight}

The foresight approach is often confused with other future-oriented activities such as forecasting, future studies, and strategic planning. The term should not be confused with forecasting, the latter which tends to focus its assumptions on how the future will turn out. Forecasting scholars also seek accuracy in their predictions about what the world will look like at some point in the future. Foresight contrasts directly with forecasting, as foresight is a process that aims to create shared visions of the future that will be supported through actions taken in the present. Thus, foresight does not seek to only predict the future, but also to get involved in creating it (UNIDO, 2005).

Foresight thus includes both qualitative and quantitative means for monitoring clues and indicators of trends and their development. These are best and most useful when directly linked to policy analysis and its implications. In this way, the foresight approach helps policy makers prepare for future opportunities (Zackiewicz \& SallesFilho, 2001).

Technological foresight assumes a dynamic reference system. This emerged in the conceptual development of evolutionary economics in the early 1980s. Combined with this way of thinking, the practice of foresight leads to interactions under consideration during a chaotic period of change. Thus, it can be used to promote the flow of knowledge among various social actors as a way to establish conflict moderation (Zackiewicz \& SallesFilho, 2001).

Foresight involves an explicit recognition that technological and scientific developments depend on choices made by actors in the present. In other words, they are not determined only by some intrinsic logic, nor do they happen independently, or randomly. These developments constitute a social process that is shaped by complex interactions among research institutes, universities, companies, governments, etc. It is a social process that, in the language of evolutionary economics, follows "trajectories", which give a sense of direction and irreversibility to advances in scientific and technological knowledge. Foresight aims to try to anticipate advancements and new positioning as a way of influencing the orientation of technological paths. In evolutionary terms, foreside focuses on moving ahead, ensuring the competitiveness and survival of research institutions and, by extension, their end users. 


\section{Kondratieff's Economic Waves and Future Scenarios Planning: an approach for organizations Marcos Ferasso and Eloisio Andrey Bergamaschi}

It should be noted that technological foresight is considered as a process and not just a set of techniques. It focuses on creating a better understanding about possible future developments and the forces that seem to shape them. Technological foresight also suggests that the future cannot be scientifically demonstrated from basic assumptions (the central point is to address the chances of development and the options for action at present), and that not passive, but rather active behavior towards the future is expected for positioning.

The literature offers several methods and approaches for exploring the future. Miles and Keenan (2003 as cited in UNIDO, 2005) cite four main groups of methods for thinking about the future: subject identification, extrapolative approach, creative approach, and prioritization approach. In this paper, we use the creative approach, focussing on the construction of future scenarios.

\subsection{Construction of future scenarios}

According to Schwartz (2000), scenarios are stories about how the world can become tomorrow, that can help us recognize and adapt to changes in our environment. The basic purpose of scenario creation is to explore 'alternative futures' that enable a better understanding of the change process (Tydeman, 1987).

Scenarios are tools for improving decision-making that have possible future environments as a background. They should not be treated as predictions that are capable of influencing the future. Instead, scenarios are vehicles that help people to learn about change. Scenarios offer alternative images about the future, rather than simply extrapolating on present trends. Scenario planning is about making choices today with an understanding of what might happen to their actions in the future.

The process of envisioning scenarios is often be compared to the process of writing a movie script, where the main idea is conceived, and the characters develop around a central theme. A number of questions must be considered when building scenarios: What are the driving forces? What is uncertain? What is inevitable?

A number of steps can be defined from these questions: 1) To identify the main theme; 2) To identify the main forces and environmental trends; 3 ) To classify the driving forces and trends according to their importance and uncertainty; 4) To select logical scenarios; 5) To add more details to the scenarios; 6) To evaluate the implications; 7) To select the main indicators and flags
(UNIDO, 2005).

Scenario building provides a wealth of insights about possibilities for the future, in a way that helps participants to radically change the way they think of the future. Participants in scenario building strive to better understand the alternative needs of likely futures, and thus are able to develop better strategies in the present (UNIDO, 2005).

Another relevant feature in the scenario building process is to consider the necessary learning time for new technologies. Technology entrepreneurs often fail to predict their own growth because they do not take learning time into account and they may not see technological growth as an analogous "evolutionary" process (Schwartz, 2000). Much of the applicability of future forecasting has been seen in the area of business management in research carried out by Schwartz (2000), who elaborated a scenario planning methodology for corporate purposes.

According to Godet and Roubelat (1996, as cited in Coelho, 2003) when building a desired scenario, it cannot be the mere expression of a group's dream. The scenario must be a description of a plausible future, revealing a consistent vision that leads to account for the historical context as well as the resources mobilized by the collectivity. Thus, Kondratieff's economic waves can serve as a basis to fostering the process of building consistent scenarios, by portraying past events that allow extrapolations to future events.

\section{Kondratieff's Economic Waves}

In the field of economics, there are two main approaches to studying economic changes and patterns that could emerge in the form of waves, effectively, mainstream and heterodox or non-orthodox. Grinin, Korotayev and Tausch (2016) divide economic cycles studies in two. For them, orthodox scholars consider long-term economics in a 'mysterious' way with multiple answers and less consensus about effectiveness of long-term studies. In the heterodox approach, there is an attempt to focus on how economic processes can work in an effective way, by considering long-term economic growth as characterized by 'cyclical' processes. On the other hand, non-orthodox scholars considered long-term for studying cyclical process of 40-60 years, specially paying attention to the emergence of new paths. Some economists disagree with the heterodox approach, since there was no previous economic scenario to study the industrialization period. Thus, a key point in the theory's 


\section{Kondratieff's Economic Waves and Future Scenarios Planning: an approach for organizations Marcos Ferasso and Eloisio Andrey Bergamaschi}

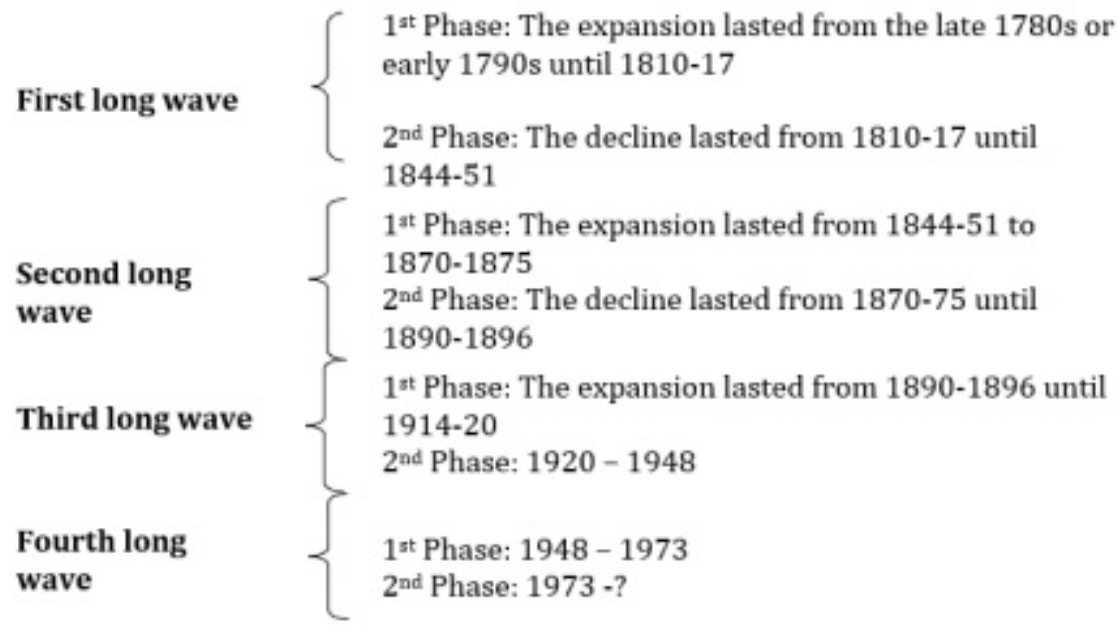

Figure 2. Kondratieff waves phases

Source: taken from Kondratieff (1935).

value is determining how long or how short Kondratieff's waves can or should become (Grinin et al., 2016).

Although the waves themselves represent patterns, there have been some attempts like Kondratieff's to determine the standards and explanations for how wave changes can occur (Grinin et al., 2016). Kondratieff conducted research focusing on studying all kinds of business cycles in market-oriented economies. Kondradieff was not the first to come up with the idea of 55-year-long waves, but he was the first to gather empirical evidence to debate and support the idea (Goldstein, 1988; Grinin et al., 2016).

Kondratieff's main interest in long waves was empirical rather than theoretical. His intention was not to constitute or lay the foundations of an appropriate theory of long waves, but rather only to reveal or demonstrate its existence based on empirical evidence from world economic history. For that, Kondratieff assembled data from several countries, seeking to examine the behavior of economic variables, such as indicators of commodity prices, iron production, imports and exports, among other things, in order to examine movements and patterns of shorter and longer waves (Kondratieff, 1935; Korotayev \& Tsirel, 2010; Nefiodow \& Nefiodow, 2014; Grinin, Korotayev \& Tausch, 2016).

In 1935, Kondratieff stated it would be impossible to precisely determine the number of years in every changing point of long waves. Analyzing data collected seeking to support his hypothesis, Kondratieff noticed a 5-7-year discrepancy in determining the point of change. Thus, he concluded these periods could be clustered and presented according to four waves (see Figure 2).

Kondratieff's contribution in The Long Waves in Economic Life (1935) corresponds with what was happening around him, going through what he considered as the first and second phases of a third long wave (LW3P1 and LW3P2). According to Rangel (2005), we are permitted to extrapolate these waves by comparing with key economic facts that occurred in the period. From 1920 to 1948, the United States grew at a rate of $3 \%$ per annum. In comparison, Europe's growth rate was $2.4 \%$ per annum during the same period and is therefore consider a time of weak growth. Conversely, in the first phase of the so-called fourth wave (LW4P1) (1948-1973) the world witnessed a period of extraordinary dynamism, where the United States tripled its production.

However, 1973 seemed to mark the end of the first phase of the fourth wave (LW4P1), with a slowdown in the world economy. The poor economic performance was even more shocking as it disrupted years of particularly intense growth. After this period, development resumed, but less significantly, meanwhile symptoms arose such as higher inflation rates, increasing unemployment, and exacerbation of protectionist tendencies in many countries, which doomed further economic integration.

Likewise, the first years after the start of the second phase of the third long wave (LW3P2) in 1921, also showed economic recovery. This in turn culminated in the disaster of 1929 - 1933 and subsequently, in the great 


\section{Kondratieff's Economic Waves and Future Scenarios Planning: an approach for organizations Marcos Ferasso and Eloisio Andrey Bergamaschi}

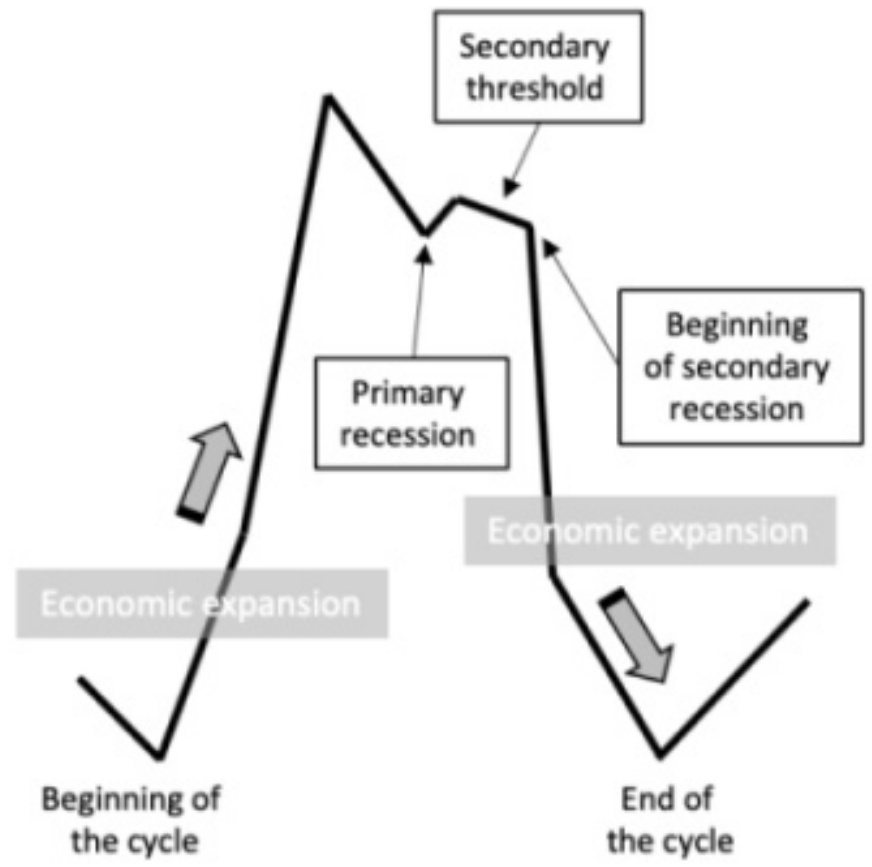

Figure 3. Four phases of Kondratieff's wave Source: built based on Hemsi (2006: 36)

depression of (LW3P2), through past World War II.

For a quick overview of the 'cyclical vision', Kondratieff waves consist of four distinct phases, as shown in Figure 3. These are: the economic growth or expansion phase, the primary recession, the intermediate phase between the first recession and the second recession, which is called the secondary threshold, and finally, the secondary recession. Considering the identified characteristics of each phase, it is possible to anticipate changes in an economy's path. Thus, one can learn to recognize the challenges and forthcoming opportunities in each phase. This attention is summarized by Kondratieff: During the downward phase of the long waves, there are many important discoveries and inventions in the technique of production and trade, which, however, are usually only widely applied in practical economic life, when the new and persistent upward phase begins (Kondratieff, 1935 as cited in Rangel, 2005).

Figure 4 presents the idealized Kondratieff wave forecast, as well as the variation in wholesale price changes in the United States until 1980.

The beginning of the decline of each long wave can be observed through several coincidences. In 1819 - Real estate market went down; 1873 -Stock Market crash of
Vienna, London, and New York; 1929 - Stock Market crash of New York, and again, in 1987, as we shall see below. Other interesting coincidences are the 25-year waves between events: 1914 - beginning of World War I; 1939 - beginning of World War II; 1964 - beginning of the Vietnam War; 1989 - fall of the Berlin Wall and consequent implosion of the Soviet Union; 2004 Beginning of the first Iraq War.

Kondratieff's waves have since been updated by scholars, with two new waves added to his earlier vision. These new waves both refer to the digital revolution, witnessed by the ascension of Information and Communication Technologies (ICTs) that have shaped economies at global scales. The passage from fifth (LW5) to sixth waves (LW6) is marked by the financial crisis of 2007-2009. The current wave is considered the 6th Kondratieff wave, and is based on renewable energies, smart grids, cloud computing, industry 4.0, the ecosystemic perspective of innovation, circular economies, and circular business models to name a few examples. All of these changes can be related to the emergence of what some people have called "the Fourth Industrial Revolution" (Schwab, 2017), which is based on big data, mobile supercomputing, intelligent robots, and renewable energies, to name a few of characteristics of this revolution. Figure 5 presents an update by adding two waves to Kondratieff's initial graph. 


\section{Kondratieff's Economic Waves and Future Scenarios Planning: an approach for organizations Marcos Ferasso and Eloisio Andrey Bergamaschi}

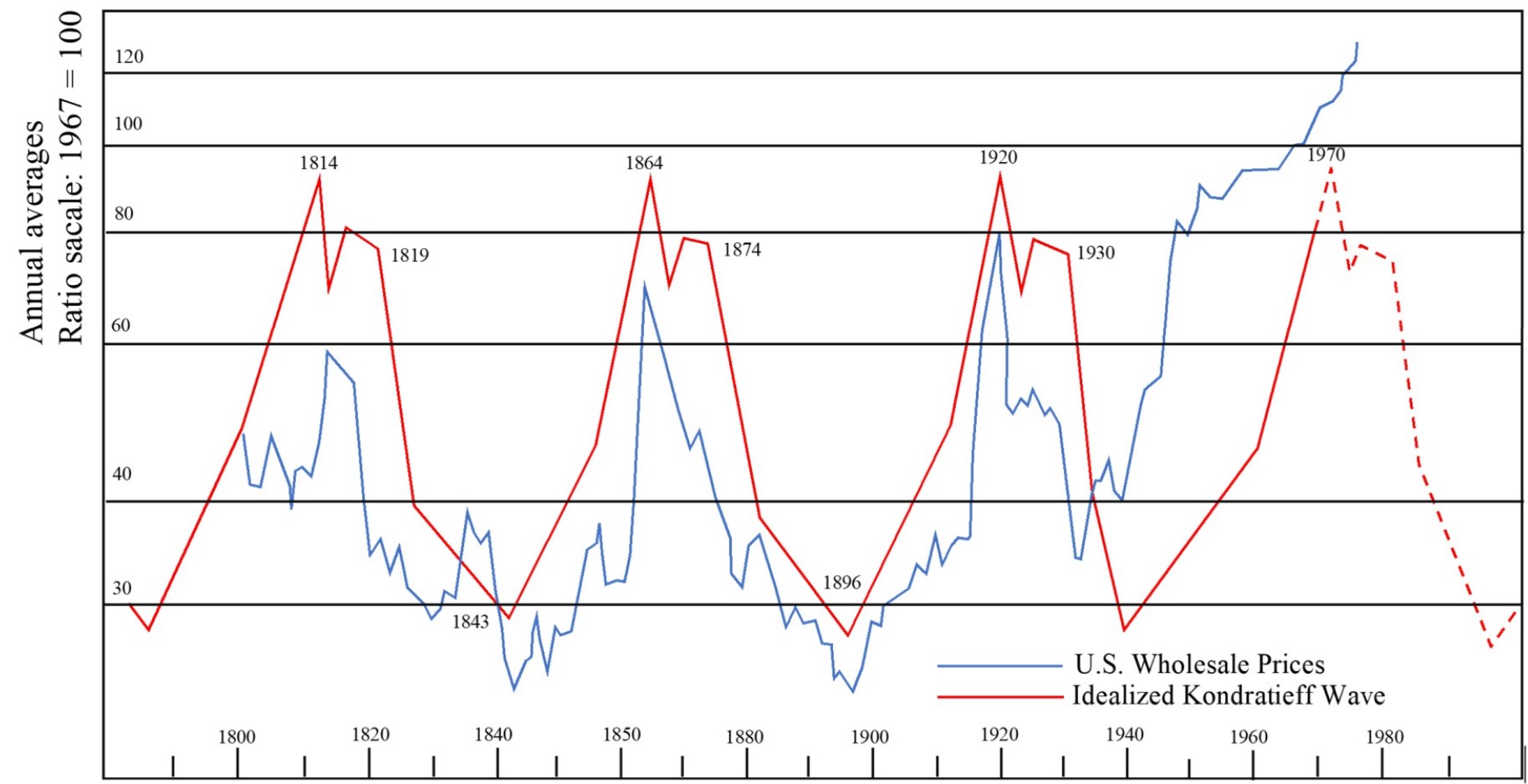

Figure 4. Kondratieff's idealized waves Source: taken from Hemsi (2006: 37)

In a meta-inference analysis of the Kondratieff's waves and considering the two new added waves, it becomes evident that rapidly developing technologies change the time in which new economic waves are forming. In short, more rapid technological development is often responsible for accelerating economic waves. At the same time, technology is often responsible for greater emerging economic wealth, as seen in the widening continuum of the red line, compared with previous waves.

While the fifth economic wave was centered on information and communication changes, the sixth is additionally represented by revolutions in biotechnology and the healthcare domain. According to this view, we also notice the assumption that is possible to link macroeconomics with innovation. as well as technology changes for the long-term thinking and assessment (Nefiodow \& Nefiodow, 2014).

According to Kondratieff (1935), long waves arise from causes that are inherent to market-oriented economies. We believe that the market-impacted behavior of these waves can therefore be used as a reference for building future scenarios. They can assist in portraying past historical series and indicate potential general directions of events, based on extrapolating recent and current behaviors to future trends.

\section{Building the Edge of Future Scenarios and Kondratieff's Waves}

We believe that future scenarios can be used constructively in combination with Kondratieff's waves. The long waves are meant to identify a pattern, so that it may help in the construction of possible scenarios. Rangel (2005) believes it is possible to imagine extrapolations from Kondratieff's time, according to subsequent data, thus revealing a fifth long wave, and more recently, the beginning of a sixth wave.

However, the evidence of economic waves lasting approximately fifty-five years came at an earlier time when data collection and communication was limited, and prior to computer use. In Rangel's (2005) approach, the impact of new ICTs is not shown in the waves' behavior. Nevertheless, since then, access to new technologies has allowed the spread of knowledge on a scale and speed never imagined before. Knowledge diffusion has thus had a direct and meaningful impact on social and economic patterns on a global scale. 


\section{Kondratieff's Economic Waves and Future Scenarios Planning: an approach for organizations Marcos Ferasso and Eloisio Andrey Bergamaschi}

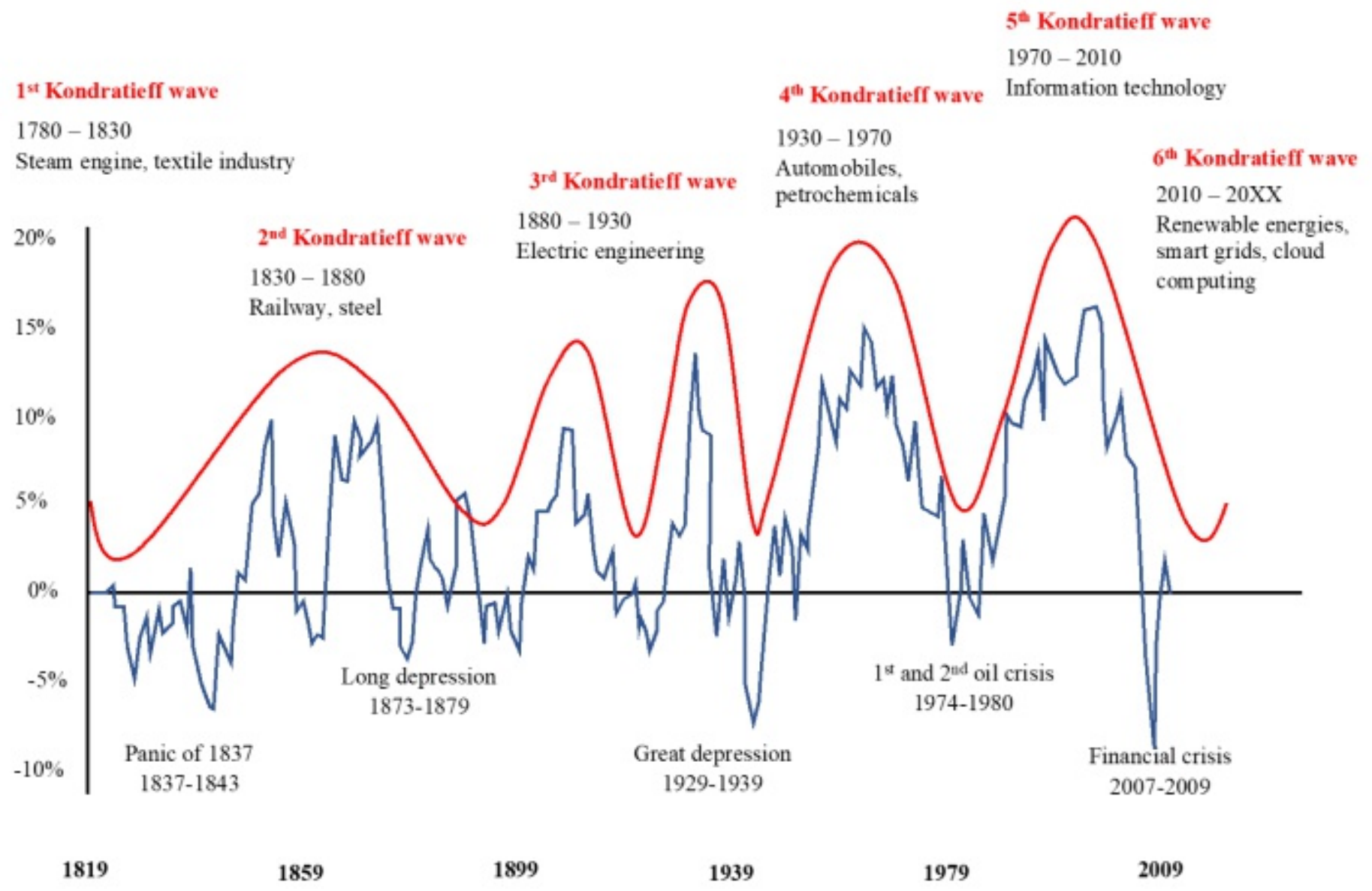

Figure 5. Kondratieff's waves updated

Source: taken from Posch and Bruckner (2017: 112)

Following the trends, we may assume that long economic waves also reduce in their duration period. In other words, the waves are occurring in a shrinking time frame. In this sense, the rapid changes can permit the faster occurrence of new business or economic opportunities, as well as threats, compared with the previous waves.

Following Kondratieff's pattern, we have left the fifth wave, even though current technologies (see in sixth wave) have not yet changed the duration. As a result, many questions arise. What are some of the challenges, opportunities and threats in the current sixth wave, according to an extrapolation of Kondratieff's model? What scenarios can be constructed from this hypothesis? Should we prepare for a possible war? What is the expected behavior of the financial markets? Are we about to collapse on a 10-15-year horizon? Considering various technological pathways, what were the innovations to be developed at the end of the sixth wave
(Figure 5)? Are these innovations being widely used in the expansion phase of the sixth wave? What impact would more widely adopting these technologies have on the economy and society?

These and many other questions could be posed based on the hypothesis that the long Kondratieff waves do indeed accurately reflect economic data. Although Figure 5 shows the fifth and sixth Kondratieff's waves (Nefiodow \& Nefiodow, 2014), these two differ from the pattern previously identified and shown in Figure 4. Beyond Kondratieff's waves model, we need to focus on the pattern identified by other scholars. Thus, Kondratieff's waves can contribute to technological assessments of organizations through time by considering technological directions and pathways.

\section{Conclusion}

The purpose of this paper has been to highlight the 


\section{Kondratieff's Economic Waves and Future Scenarios Planning: an approach for organizations Marcos Ferasso and Eloisio Andrey Bergamaschi}

contribution Kondratieff's theory of long economic waves can provide to help elaborate future scenarios. The authors believe it can be used to consider the social, economic, and technological effects that these waves have presented throughout history.

The study of long waves allows us to identify macro-level trends of events. The practical challenge in application is how to possibly use these elements in the process of building future scenarios. The study of long economic waves does not presuppose a certain future to come, but rather can indicate possible signs based on empirical evidence from past events. As Kondratieff noted, the causes for occurring waves are inherent to the conventional market-oriented economic system (in Kondratieff's time). In today's resource-based economic thinking, based on a post-scarcity world, with the introduction of current characteristics, such as Industry 4.0, cryptocurrencies, and circular economies, it may be useful to consider the shrinking of Kondratieff's waves to predict what could be the waves emergence and when they would occur.

Through this reflection, we conclude that, although there is a close relation between thematic studies of the future, and predictions about economic behavior in Kondratieff's wave model, we still need to broaden our current understanding about the relation between long economic waves and their impact on the construction of future scenarios.

With the scope established, this article has the following limitations. Kondratieff's approach is considered as nonorthodox or heterodox in economics of planning future economic scenarios. Although we are not determining a 'one model fits all' view with this research, we are also not proposing an approach that leads only to certain results, noting the criticism of this by Nefiodow and Wilenius (2017). Thus, this manuscript stressed a basic need for better preparing decision makers for taking a long-path approach when dealing with scenario planning.

Finally, we would recommend experimentation with future scenario planning in conjunction with Kondratieff's economic waves for organizations devoted to technological forecasting. The consideration of Kondratieff's waves can contribute to scenario planning in technological assessment by providing possible directions for technological development.

\section{Acknowledgements}

Marcos Ferasso would like to thank the anonymous reviewers and TIM Review editors for their insightful suggestions that improved this manuscript, and to Sandro Nystrom Lozekam for his support in text revision.

\section{References}

Blair, P. 1994. Technology assessment: current trends and the myth of a formula. Federation of American Scientists.

https://ota.fas.org/technology_assessment_and_cong ress/blair/

Castro, A.M.G. \& Lima, S.M.V. 2001. Curso de capacitação de equipes para estudos prospectivos de cadeias produtivas industriais. Brasilia: MDIC/STI.

Coates, J. 2003. Why Study the Future? Research Technology Management. 2003.

Coelho, G.M. 2003. Prospecção tecnológica: metodologias e experiências nacionais e internacionais. Rio de Janeiro: INT/Finep/ANP Projeto CT-Petro Tendências Tecnológicas. http://www.davi.ws/prospeccao_tecnologica.pdf

Cornish, E. 2004. Futuring: The exploration of the future. Maryland: World Future Society.

FOREN, Foresight for Regional Development Network. 2001. A practical guide to regional foresight. Edited by JRC-IPTS, PREST, CM International, Sviluppo Italia.

Freeman, C. \& Perez, C. 1998. Structural crises of adjustment: business cycles and investment behaviour, In: Dosi, G. (Org.). Technical Change and Economic Theory. London: Pinter Publishers: 38-66.

Goldstein, J.S. 1988. Long Cycles: Prosperity and War in the Modern Age. Yale University Press: New Haven and London.

Grinin, L., Korotayev, A., \& Tausch, A. 2016. Kondratieff waves in the world system perspective. In Economic Cycles, Crises, and the Global Periphery, Springer, Cham: 23-54.

Hemsi, R. 2006. Previsão de Inovação Tecnológica e Ciclos Econômicos: uma abordagem histórica. Revista de Economia Política e História Econômica, v. 03, n. 5: 31-43.

https://sites.google.com/site/rephe01/rephe05textoh emsi.pdf

Knorr, K. E., \& Verba, S. 2019. International System: Theoretical Essays (Vol. 5539). Princeton University Press. 


\section{Kondratieff's Economic Waves and Future Scenarios Planning: an approach for organizations Marcos Ferasso and Eloisio Andrey Bergamaschi}

Kondratieff, N. 1935. The Long Waves in Economic Life. The Review of Economic Statistics, v. 17, n. 6: 105-115.

Korotayev, A. V., \& Tsirel, S. V. 2010. A spectral analysis of world GDP dynamics: Kondratieff waves, Kuznets swings, Juglar and Kitchin cycles in global economic development, and the 2008-2009 economic crisis. Structure and Dynamics, 4(1).

Masini, E. \& Samset, K. 1975. Recommendations of the WFSF General Assembly. WFSF Newsletter, June: 15.

MDIC/STI. 2001. Programa Brasileiro de Prospectiva Tecnológica Industrial: Plano de ação.

Miles, I., Keenan, M. \& Kaivo-Oja, J. 2002. Handbook of knowledge society foresight. Manchester: Prest.

Nefiodow, L. A. \& Wilenius, M. 2017. Patterns of the future: Understanding the next wave of global change. World Scientific.

Nefiodow, L. A., \& Nefiodow, S. 2014. The sixth Kondratieff: The new long wave in the global economy. Amazon.

Posch, Gerhard \& Bruckner, Jürgen. 2017. Schweißtechnik im Zeichen von Internet of Things und Industrie 4.0. Schweiss- und Prüftechnik. v. 70: 112121.

Rangel, I. 2005. Ignácio Rangel: obras reunidas. Rio de Janeiro: Contraponto.

Salles-Filho, S.L.M., Bonacelli, M. \& Mello, D. 2001. Instrumentos de apoio à definição de políticas em biotecnologia. Brasília: MCT; Rio de Janeiro: FINEP.

Schwab, K. 2016. The fourth industrial revolution. Geneva: World Economic Forum.

Schwartz, P. 2000. A Arte da Visão de Longo Prazo: Planejando o futuro em um mundo de incertezas. São Paulo: Best Seller.

Tydeman, J. 1987. Futures Methodologies Handbook. Canberra: Australian Govt. Pub. Service for Commission for the Future.

UNIDO. 2005. Technology Foresight Manual. Vienna. http://www.research.gov.ro/img/files_up/1226911327 TechFor_1_unido.pdf

Zackiewicz, M. \& Salles-Filho, S. 2001. Technological foresight: um instrumento para política científica e tecnológica. Parcerias Estratégicas, v. 6, n. 10, pp.144161.

\section{About the Authors}

M. Ferasso earned his Bachelor Diploma in Management from University of the West of Santa Catarina (Brazil) in 2002, his Specialization Diploma in Business Management from UNOESC (Brazil) in 2005, his Specialization Diploma in Local Development from International Labour Organization/United Nations (Italy) in 2006, earned his M.Sc. in Management from UFRGS (Brazil) in 2009, with an exchange period as visiting researcher at Euromed-Marseille Ecole de Management (France), and earned his Ph.D. in Management from Federal University of Parana (Brazil) in 2018, with an exchange period as visiting researcher at Forsyth Technical Community College (USA). He concluded his first Postdoctorate at Meridional Faculty -IMED (Brazil) and the second at KEDGE Business School Marseilles (France). He is currently Assistant Professor at Unochapeco University (Brazil).

E.A. Bergamaschi earned his Bachelor Diploma in Business Management and Information Systems from Pontifical Catholic University of Rio Grande do Sul (Brazil) in 2002, his M.Sc. in Management from Federal University of Rio Grande do Sul (Brazil) in 2008, and his Specialization Diploma in Computer Science from Federal University of Rio Grande do Sul (Brazil) in 2010. Currently, he is Manager at SESI Innovation Institute (Brazil).

Citation: Ferasso, M. and Bergamaschi, E.A. Kondratieff's Economic Waves and Future Scenarios Planning: an approach for organizations. Technology Innovation Management Review, 10(2): 51-61.

http://doi.org/10.22215/timreview/1327

(cc) BY

Keywords: Future studies, Foresight, Strategic Planning, Economic waves, Kondratieff. 